\title{
Sequential Formation of a Ternary Complex among Dihexylammonium, Cucurbit[6]uril and Cyclodextrin with Positive Cooperativity
}

Mikhail V. Rekharsky, ${ }^{\dagger}$ Hatsuo Yamamura, ${ }^{\ddagger}$ Masao Kawai, ${ }^{\ddagger}$ Issey Osaka, ${ }^{\circledR}$ Ryuichi Arakawa, ${ }^{\Uparrow}$ Akihiro Sato, ${ }^{\ddagger}$ Young Ho Ko, ${ }^{\S}$ N. Selvapalam, ${ }^{\S}$ Kimoon Kim, ${ }^{*}$ and Yoshihisa Inoue ${ }^{*, \dagger}$

${ }^{\dagger}$ The Entropy Control Project, ICORP, JST, 4-6-3 Kamishinden, Toyonaka 560-0085, Japan,

*Graduate School of Technology, Nagoya Institute of Technology, Gokiso-cho, Showa-ku Nagoya 466-8555, Japan, 'Department of Applied Chemistry, Kansai University, Yamatecho,

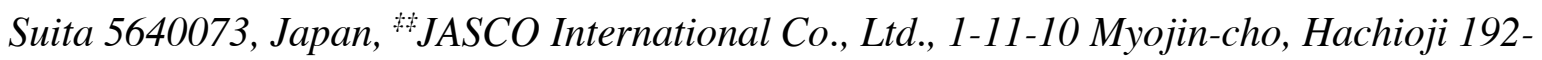
0046, Japan, and ${ }^{\S}$ Center for Smart Supramolecules, Pohang University of Science and Technology, San 31 Hyojadong, Pohang 790-784, Korea

\section{Contents}

1. ESI-MS 2

$\begin{array}{ll}\text { 2. NMR } & 7\end{array}$

3. Calorimetry 19 


\section{ESI-MS Spectral Data for the Ternary Complex Formation of Dihexylamine (DHA) with Cucurbituril (CB[6]) and $\beta$-Cyclodextrin (CD)}

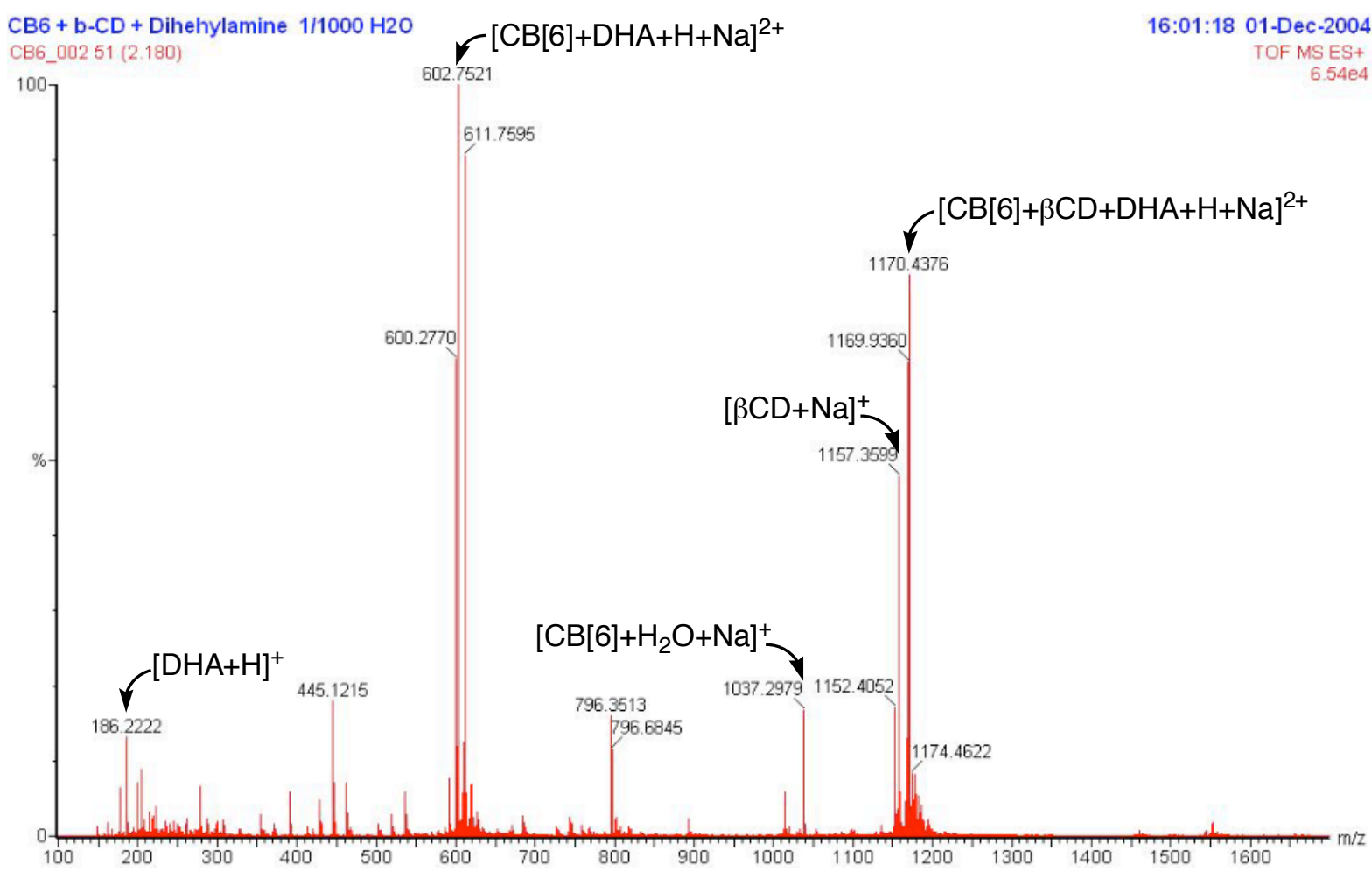

Figure S1-1. ESI-MS Spectra of a Mixture of DHA, CB[6], and CD (5 nM DHA $2 \mathrm{HCl}+$ $5 \mathrm{nM} \mathrm{CB}[6]+5 \mathrm{nM} \alpha-\mathrm{CD}$ in $\mathrm{H}_{2} \mathrm{O}$ containing $20 \mathrm{nM} \mathrm{NaCl}$ )

The CB-CD-DHA ternary supramolecular complex was clearly detected as dicationic $[\mathrm{CB}[6]+\beta \mathrm{CD}+\mathrm{DHA}+\mathrm{H}+\mathrm{Na}]^{2+}$ species, while the other component species as mono- and dicationic fragment peaks, as indicated above. 
CB6 + b-CD + Dihehylamine $1 / 1000 \mathrm{H} 2 \mathrm{O}$ CB6_00251 (2.180)

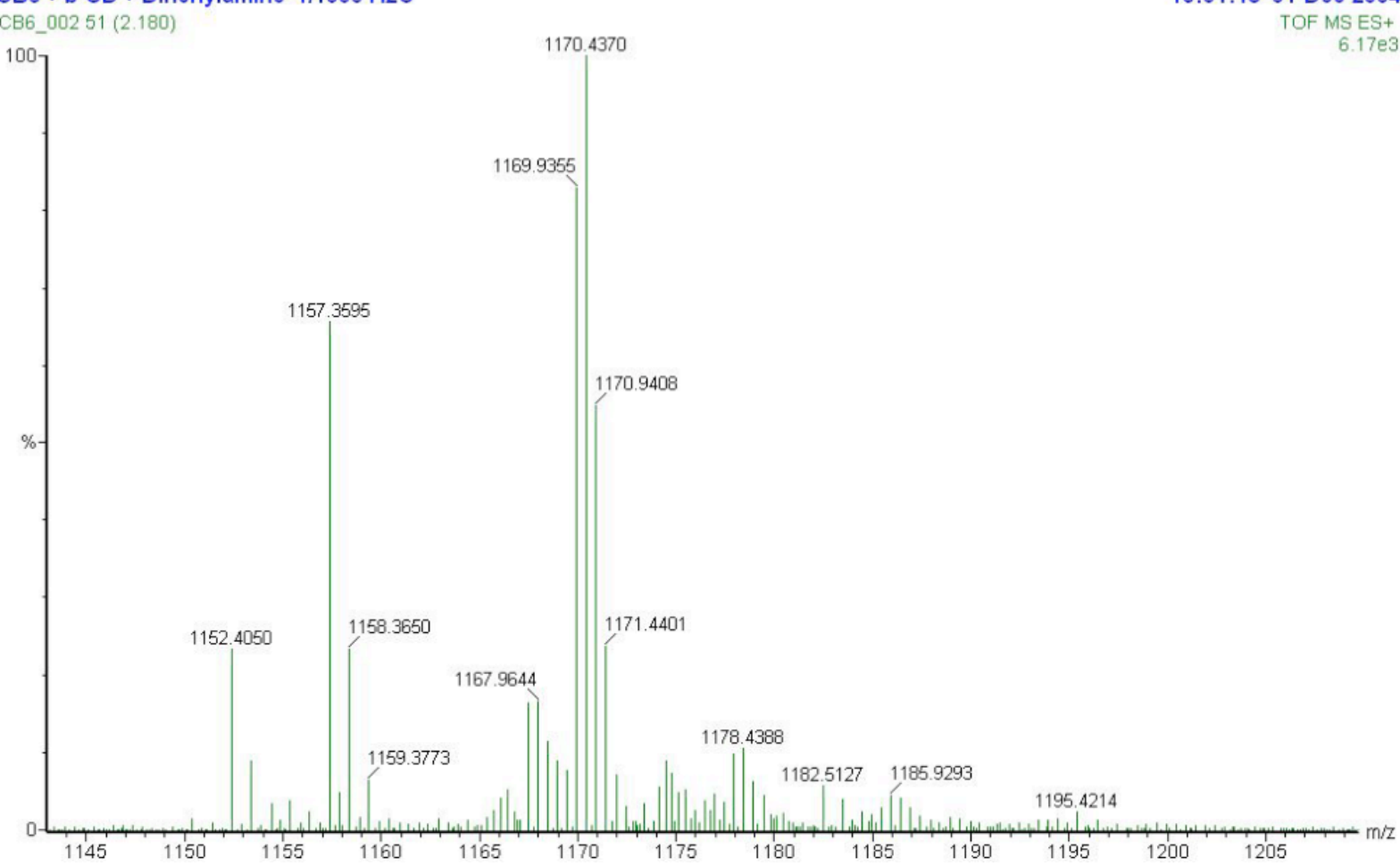

Figure S1-2. ESI-MS Spectra of $[\mathrm{CB}[6] \cdot \mathrm{DHA} \cdot \beta-\mathrm{CD} \cdot \mathrm{Na}]^{2+}$ Complex (Enlargement 1) 
$\mathrm{CB} 6+\mathrm{b}-\mathrm{CD}+$ Dihehylamine $1 / 1000 \mathrm{H} 2 \mathrm{O}$

16:10:30 01-Dec-2004 CB6_10241 (1.757)

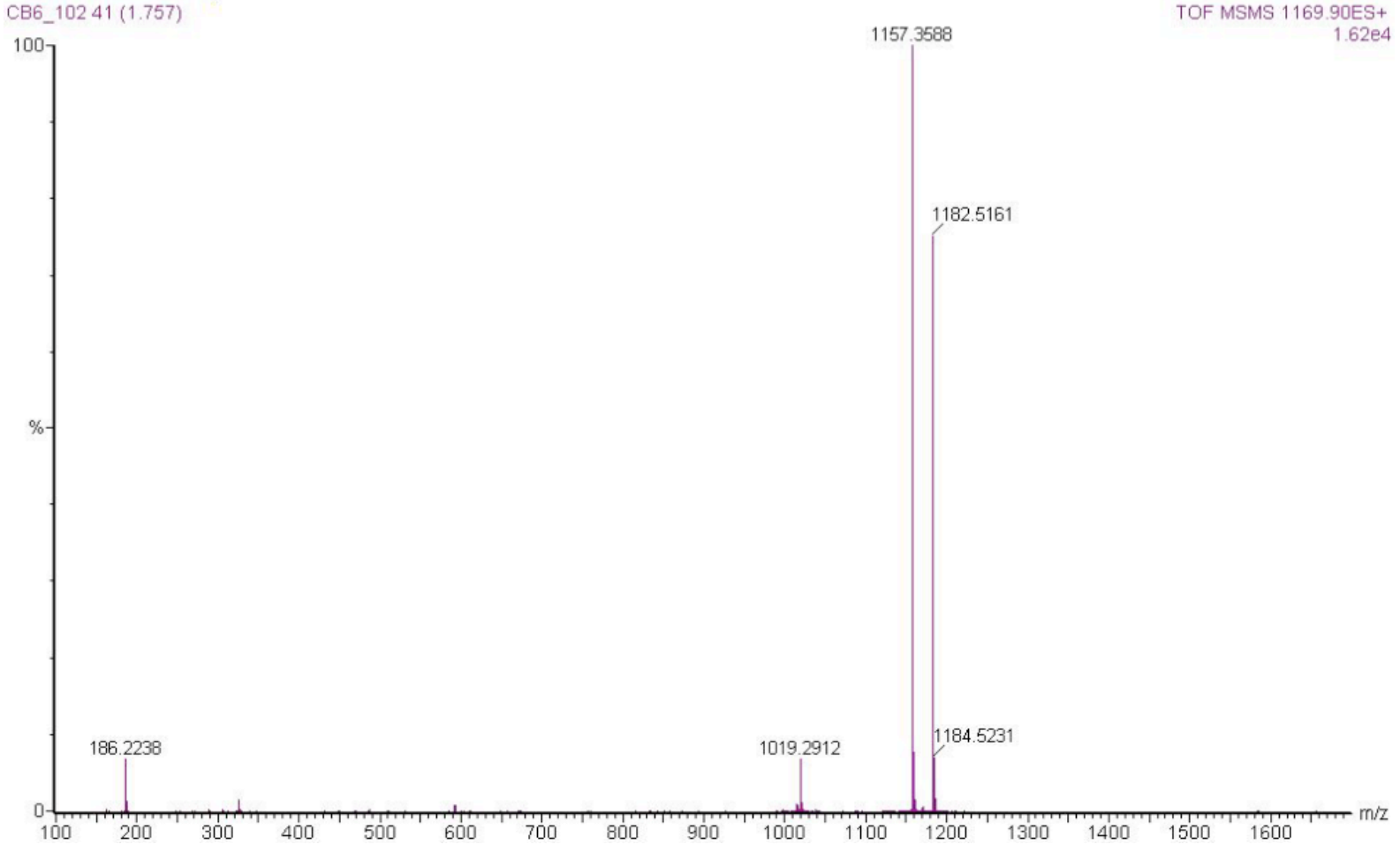

Figure S1-3. ESI-MS Spectra of $[\mathrm{CB}[6] \cdot \mathrm{DHA} \cdot \beta-\mathrm{CD} \cdot \mathrm{Na}]^{2+}$ Complex 


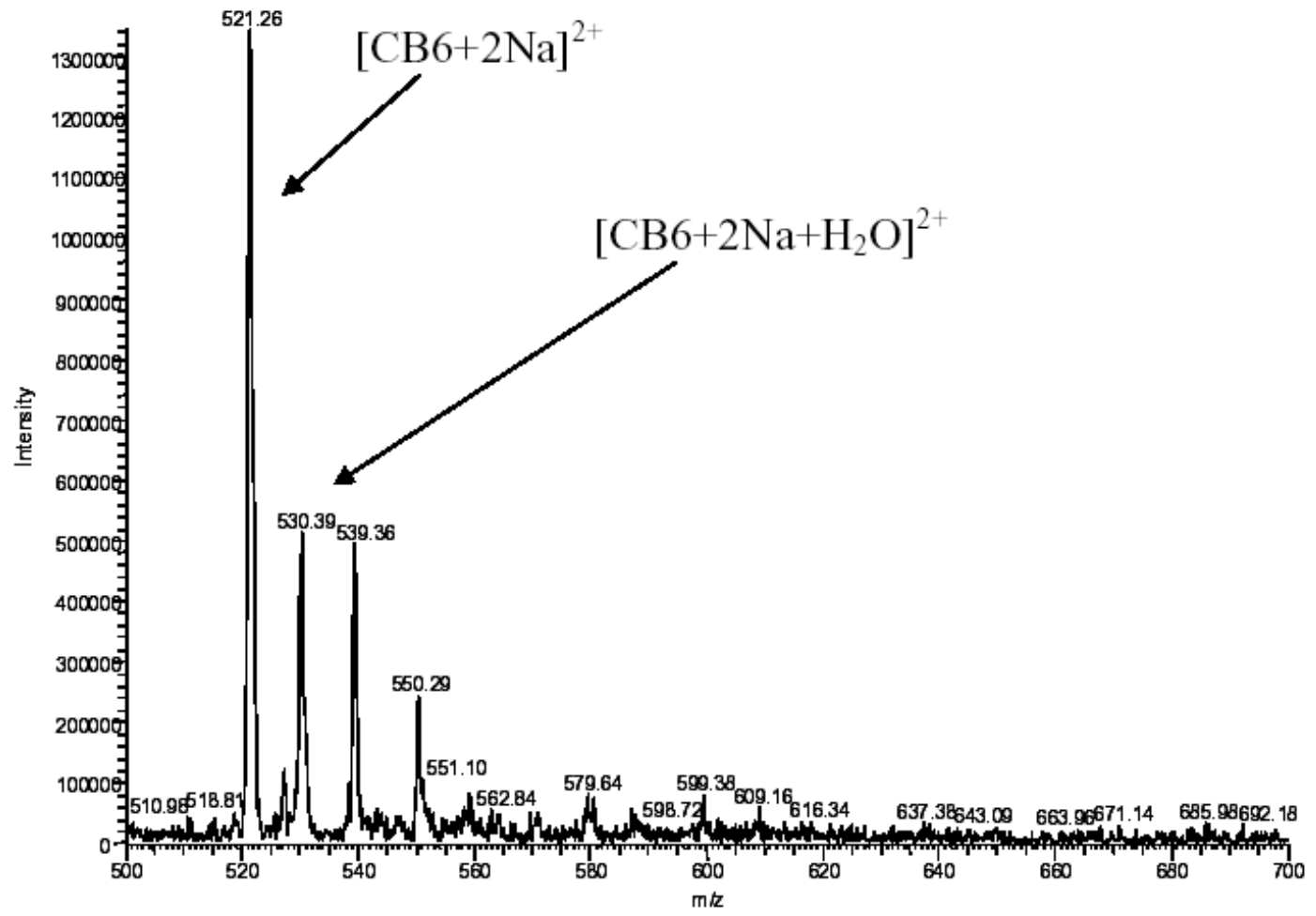

Figure S1-4. ESI-MS Spectra of $[\mathrm{CB}[6] \cdot 2 \mathrm{Na}]^{2+}$ Complex 


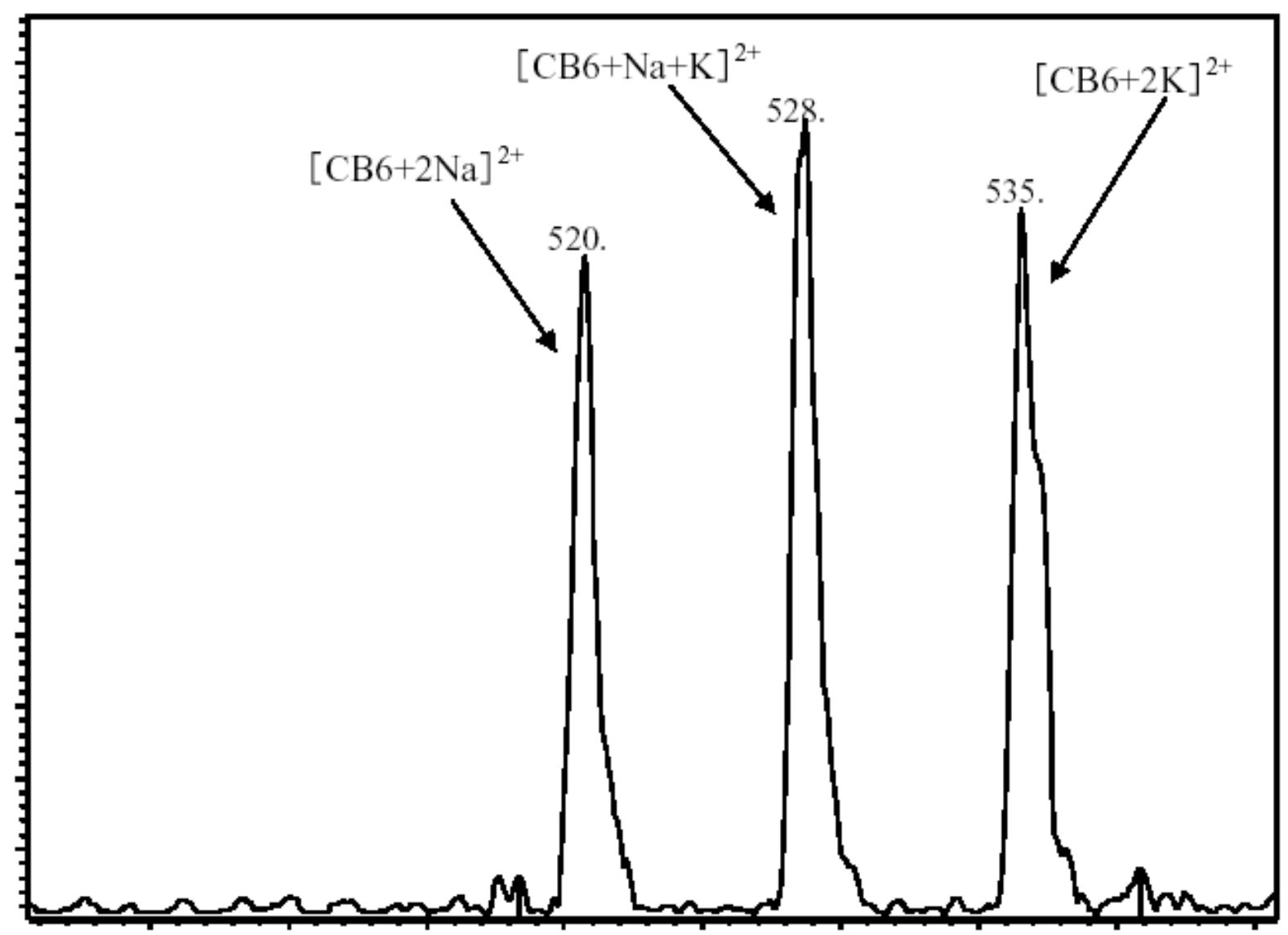

Figure S1-5. Results of ESI-MS study to illustrate that $\mathrm{CB}[6]$ always exists in aqueous solution as di-cationic species even if different cations are in the solution. 
2. NMR Spectral Data for the Stepwise Ternary Complex Formation of Dihexylamine (DHA) with Cucurbituril (CB[6]) and Cyclodextrins (CD)

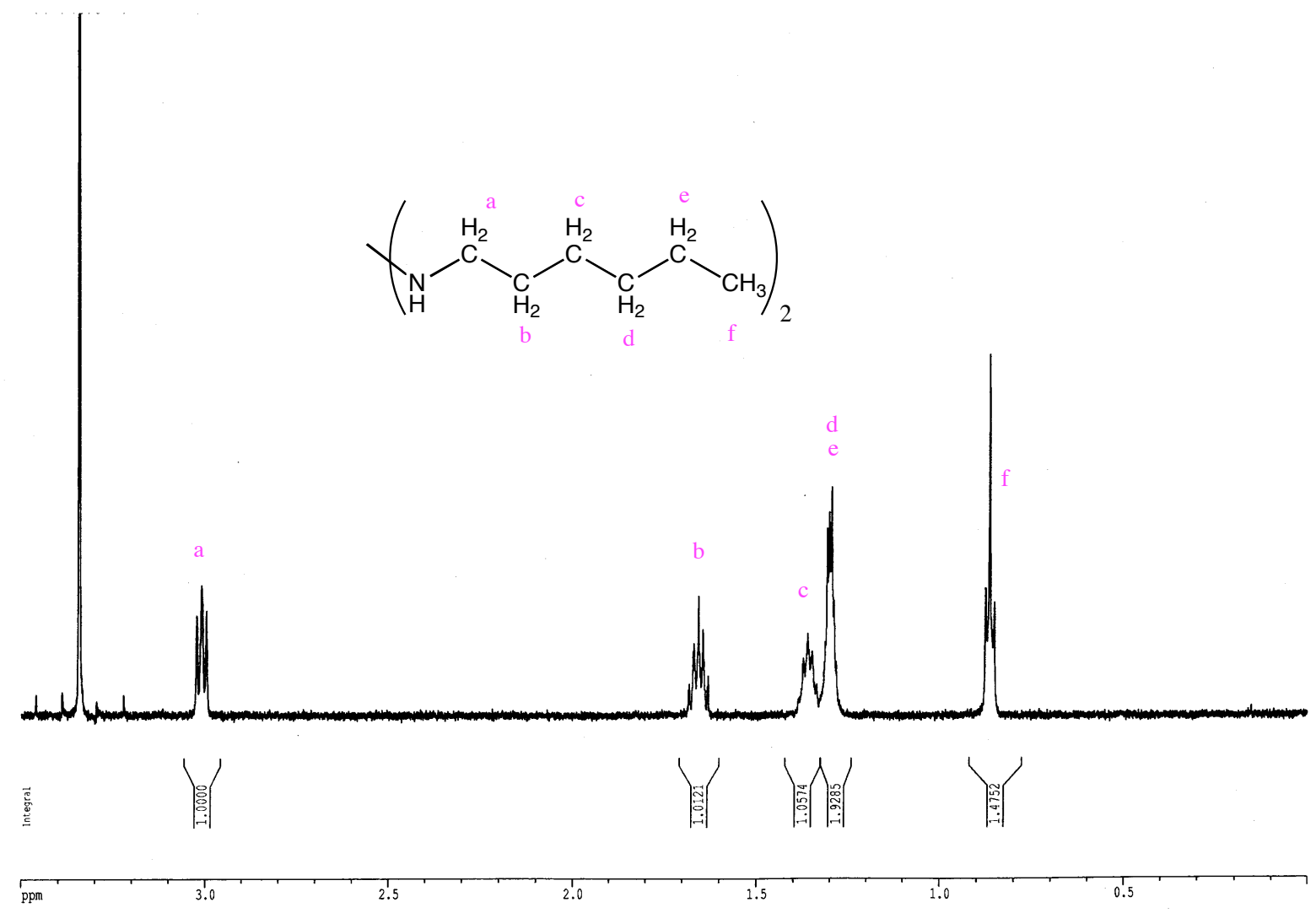

Figure S2-1. 1D ${ }^{1} \mathrm{H}$ NMR spectrum of DHA (1 $\mathrm{mM} \mathrm{DHA}$ in $\mathrm{D}_{2} \mathrm{O}$ containing $4 \mathrm{mM} \mathrm{HCl}$ and $0.2 \mathrm{M} \mathrm{NaCl}$ ) 


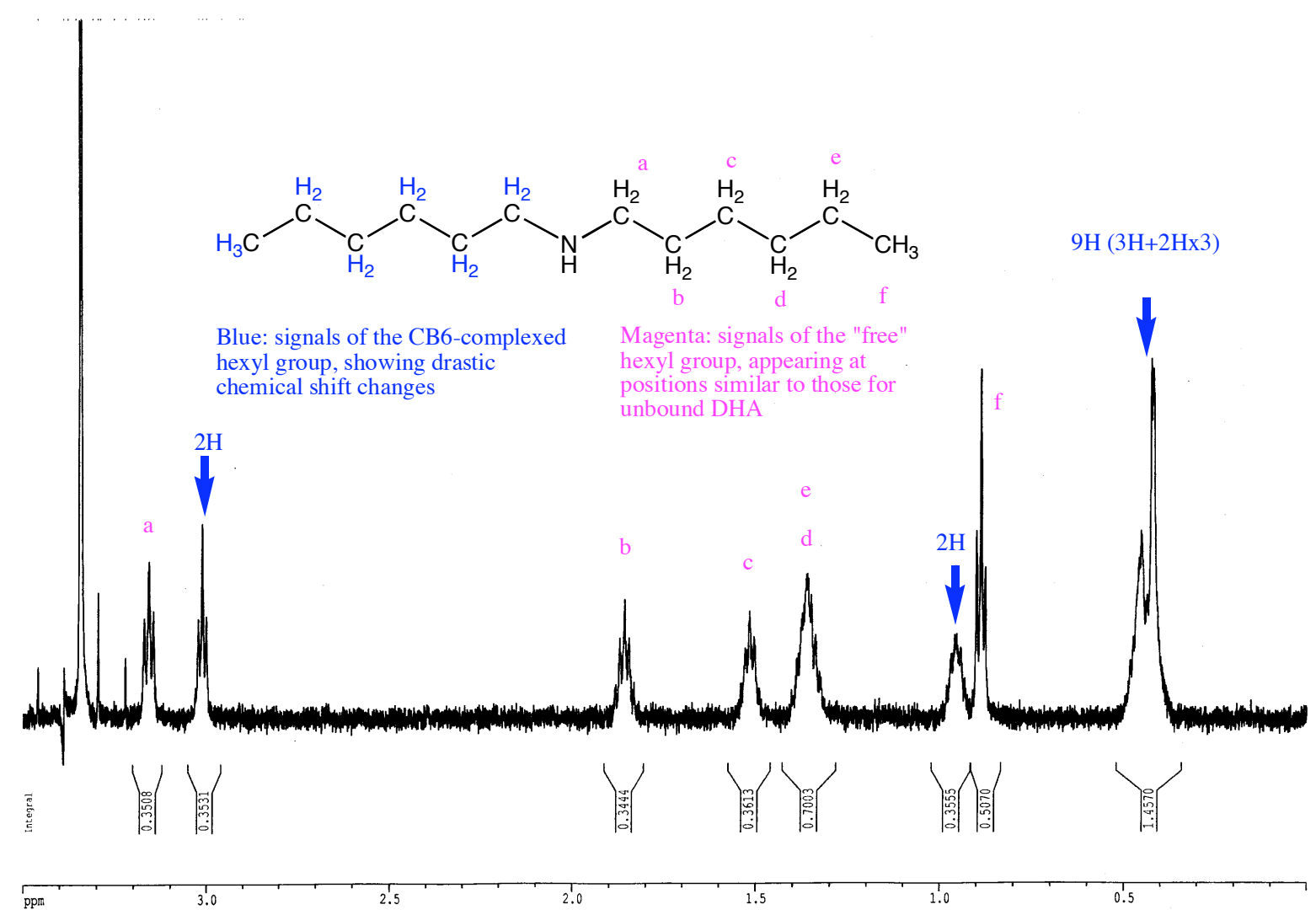

Figure S2-2. Dihexylamine signals in $1 \mathrm{D}{ }^{1} \mathrm{H}$ NMR spectrum of a mixture of DHA and $\mathrm{CB}[6]\left(1 \mathrm{mM} \mathrm{DHA}+1.4 \mathrm{mM} \mathrm{CB}[6]\right.$ in $\mathrm{D}_{2} \mathrm{O}$ containing $4 \mathrm{mM} \mathrm{HCl}$ and $\left.0.2 \mathrm{M} \mathrm{NaCl}\right)$

Compared to the chemical shifts of "free" DHA (Figure S1), each set of the aliphatic protons in the two hexyl chains are split (due to the slow guest exchange); halves of the signals (blue) are drastically upfield-shifted, while the other halves (magenta) show only small downfield shifts (particularly for $\mathrm{Ha}, \mathrm{Hb}$, and $\mathrm{Hc}$, shown in magenta). These changes clearly indicate that only one of the two hexyl groups is exclusively included by $\mathrm{CB}[6]$, leaving the other outside the $\mathrm{CB}[6]$ cavity. 


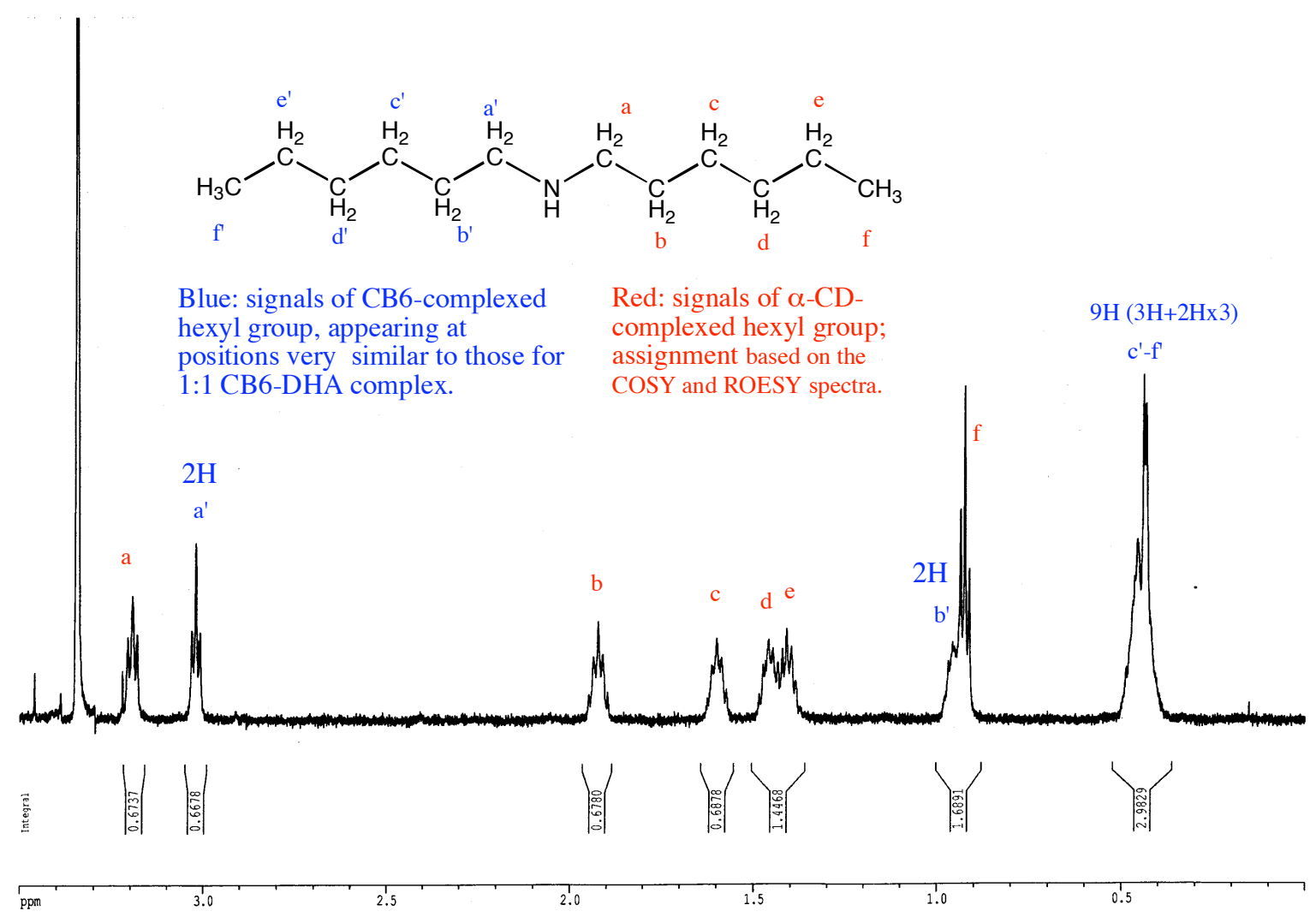

Figure S2-3. Dihexylamine signals in the $1 \mathrm{D}{ }^{1} \mathrm{H}$ NMR spectrum of a mixture of DHA, $\mathrm{CB}[6]$, and $\alpha-\mathrm{CD}\left(1 \mathrm{mM} \mathrm{DHA}+1.5 \mathrm{mM} \mathrm{CB}[6]+1.5 \mathrm{mM} \alpha-\mathrm{CD}\right.$ in $\mathrm{D}_{2} \mathrm{O}$ containing $4 \mathrm{mM}$ $\mathrm{HCl}$ and $0.2 \mathrm{M} \mathrm{NaCl}$ )

The signals of $\mathrm{CB}[6]$-complexed hexyl group do not show any further shift changes upon addition of $\alpha-\mathrm{CD}$, indicating very strong complexation of the first hexyl with $\mathrm{CB}[6]$. No competitive inclusion between $\mathrm{CB}[6]$ and $\alpha-\mathrm{CD}$ seems to occur.

The protons of the other hexyl group included in $\alpha$-CD show moderate downfield shifts and $\mathrm{Hd}$ and $\mathrm{He}$ are separated. 


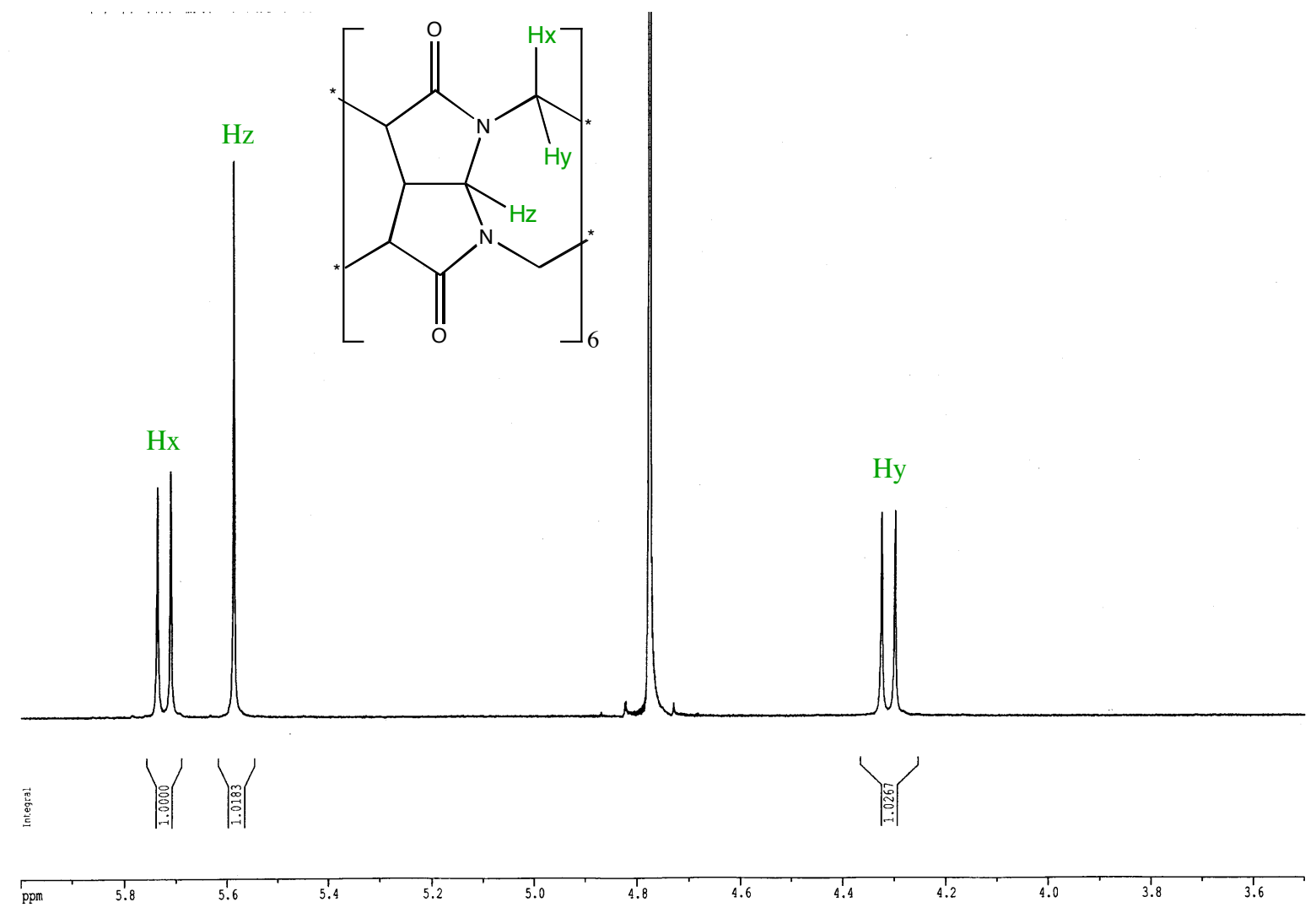

Figure S2-4. $1 \mathrm{D}{ }^{1} \mathrm{H}$ NMR of $\mathrm{CB}[6]$ (2.4 $\mathrm{mM} \mathrm{CB}[6]$ in $\mathrm{D}_{2} \mathrm{O}$ containing $\left.0.2 \mathrm{M} \mathrm{NaCl}\right)$ 


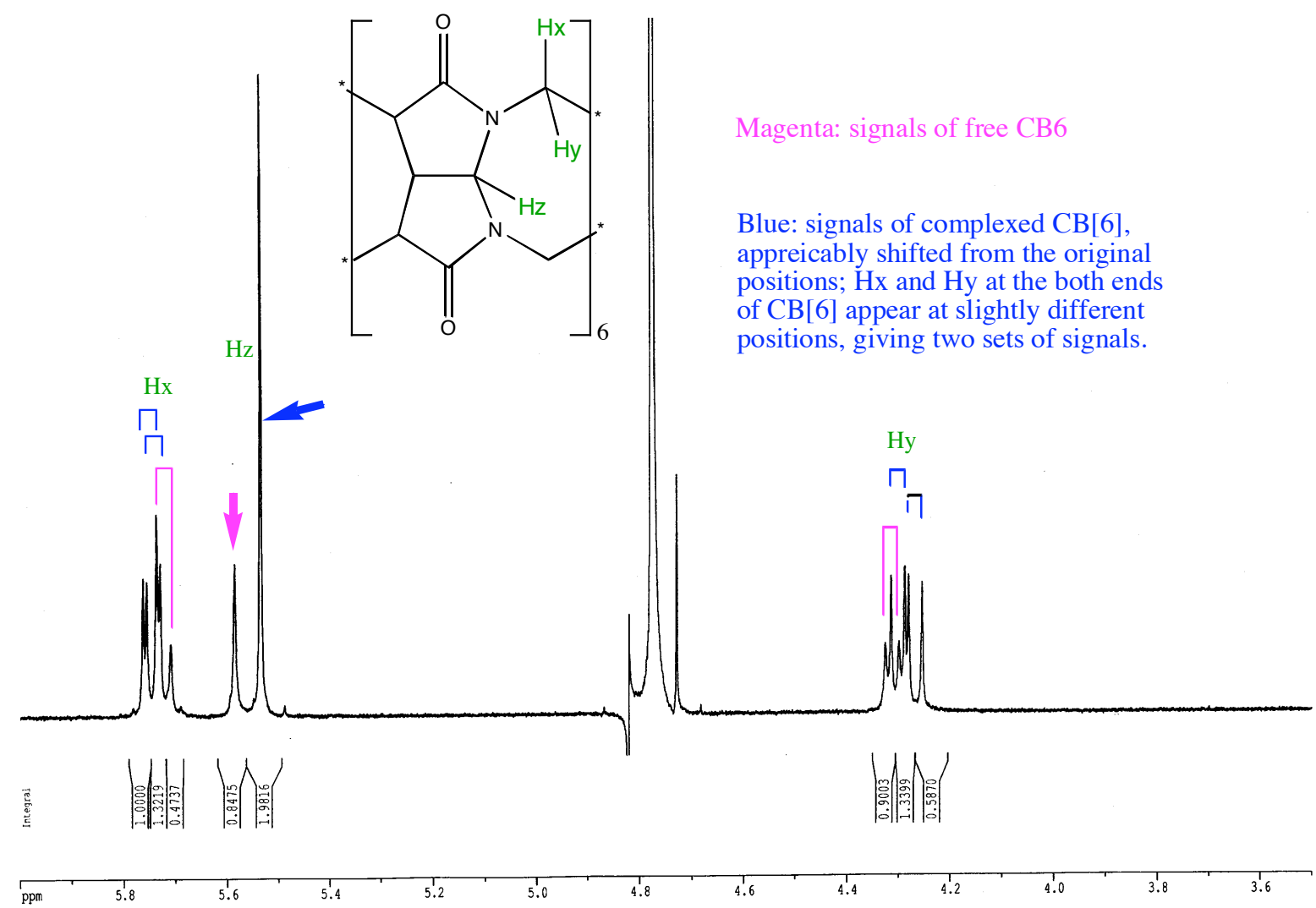

Figure S2-5. $\mathrm{CB}[6]$ signals in $1 \mathrm{D}{ }^{1} \mathrm{H}$ NMR spectrum of a mixture of DHA and $\mathrm{CB}[6]$ (1 $\mathrm{mM} \mathrm{DHA}+1.4 \mathrm{mM} C B[6]$ in $\mathrm{D}_{2} \mathrm{O}$ containing $4 \mathrm{mM} \mathrm{HCl}$ and $0.2 \mathrm{M} \mathrm{NaCll}$ )

Because of the use of an excess amount of CB[6] over DHA, free (magenta) and complexed (blue) $\mathrm{CB}[6]$ give separate signals, which are clearly assigned from their chemical shifts. The separate signals indicate a slow exchange of DHA included in CB[6].

Compared to the relevant protons of free $\mathrm{CB}[6], \mathrm{Hx}$ is shifted to the downfield, whilst Hy and $\mathrm{Hz}$ show upfield shifts upon inclusion of DHA.

Interestingly, $\mathrm{Hx}$ and $\mathrm{Hy}$ of complexed $\mathrm{CB}[6]$ (blue) are split to two sets of signals, while $\mathrm{Hz}$ gives one singlet signal, indicating that the two portal protons are differentiated upon complexation of DHA. 


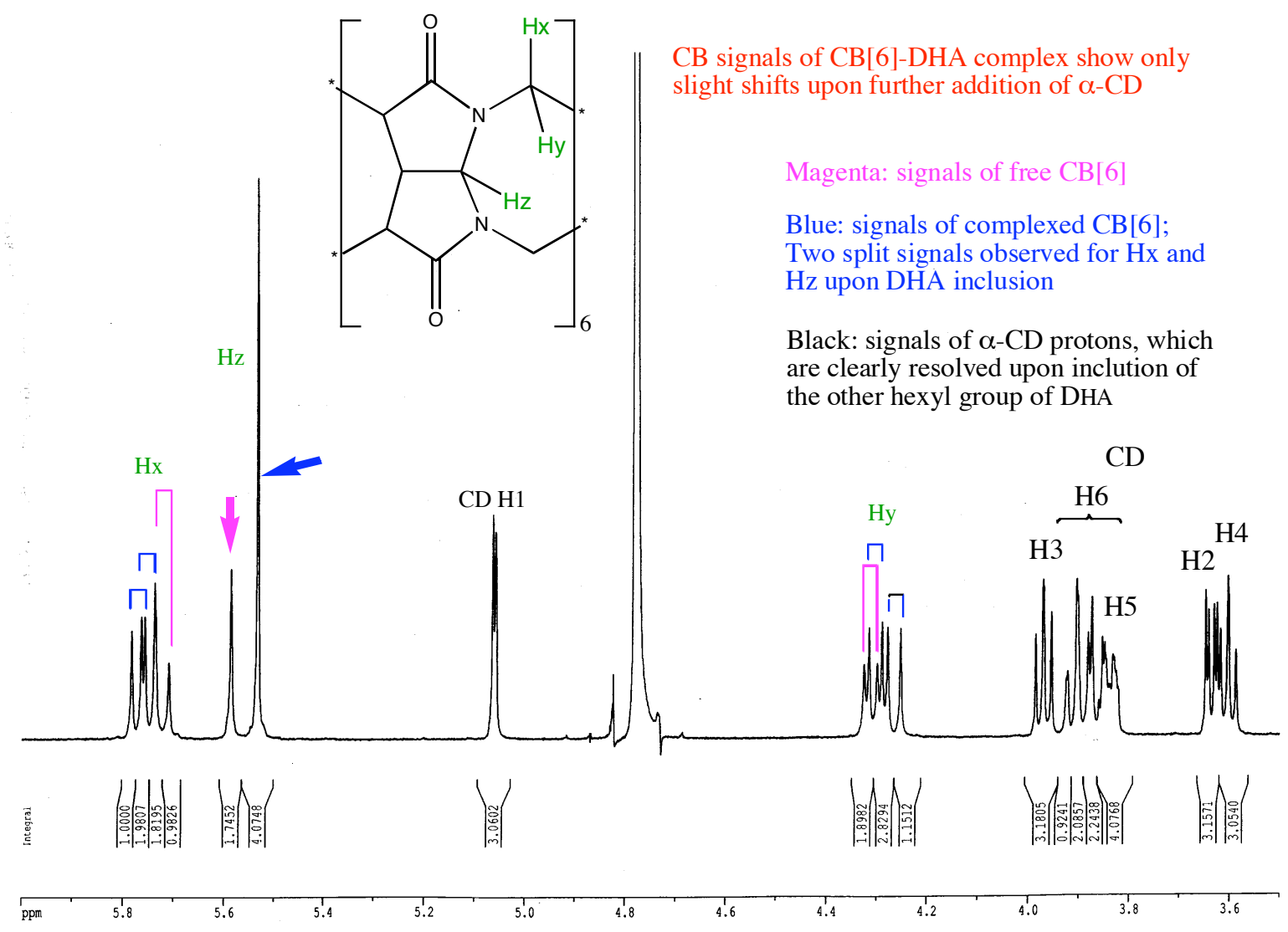

Figure S2-6. $\mathrm{CB}[6]$ signals in $1 \mathrm{D}^{1} \mathrm{H}$ NMR spectrum of a mixture of $\mathrm{DHA}, \mathrm{CB}[6]$, and $\alpha-C D\left(1 \mathrm{mM} \mathrm{DHA}+1.5 \mathrm{mM} \mathrm{CB}[6]+1.5 \mathrm{mM} \alpha-C D\right.$ in $\mathrm{D}_{2} \mathrm{O}$ containing $4 \mathrm{mM} \mathrm{HCl}$ and $0.2 \mathrm{M} \mathrm{NaCl})$

Further addition of $\alpha-\mathrm{CD}$ to the solution of DHA $+\mathrm{CB}[6]$ (Spectrum 5) causes slight but appreciable changes in DHA's Hx and Hy, due to the inclusion complexation of the other hexyl group by $\alpha-\mathrm{CD}$, giving a ternary complex. 
<smiles>CCCCCCNCCCCCC</smiles>

Blue: signals of the hexyl group inlcuded in $\mathrm{CB}[6]$

Red: signals of the hexyl group included by $\alpha$-CD (assignment based on ROESY)

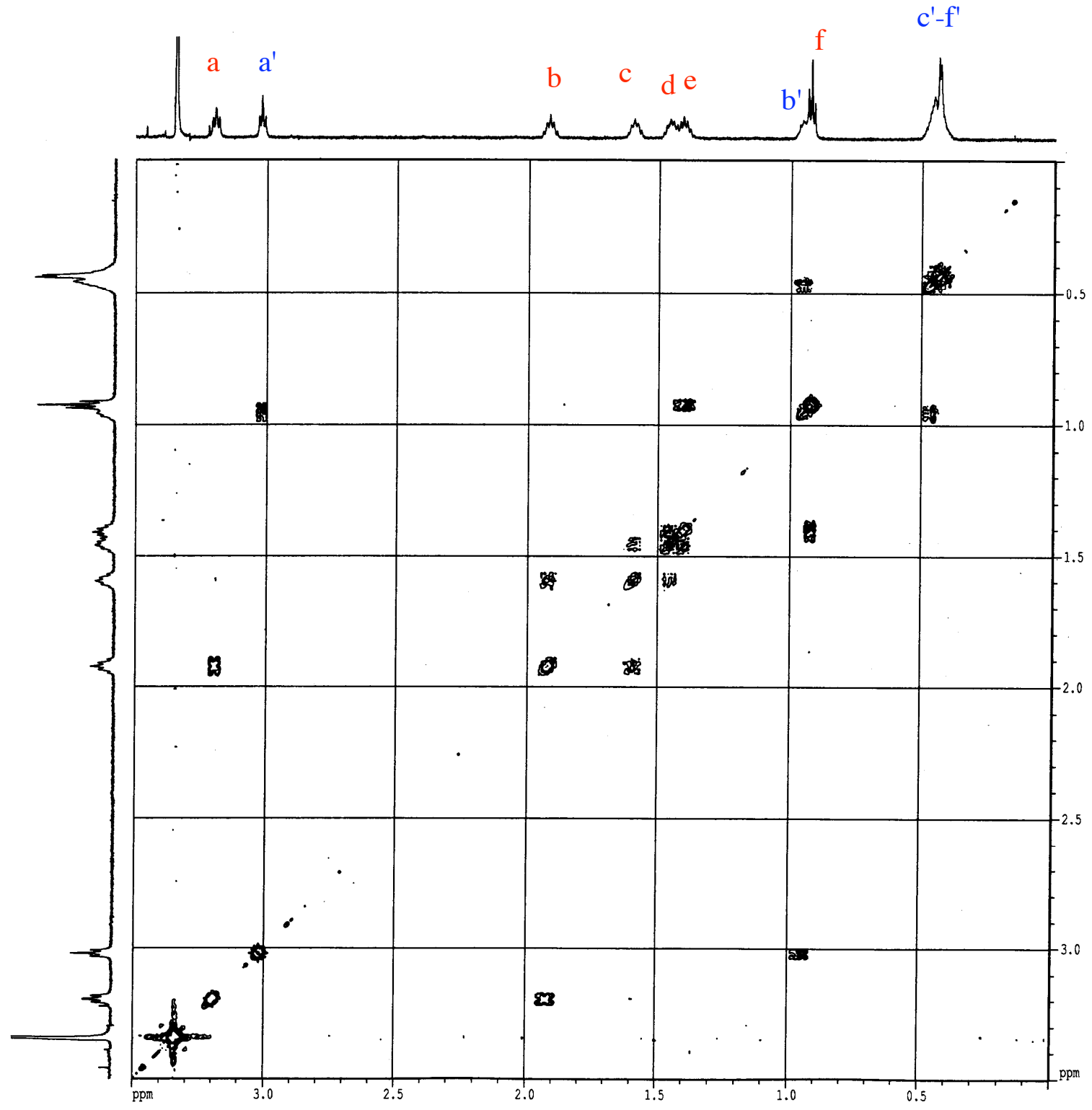

Figure S2-7. COSY spectrum of a mixture of DHA, CB[6], and $\alpha-C D(2 \mathrm{mM}$ $\mathrm{DHA} \cdot 2 \mathrm{HCl}+2.4 \mathrm{mM} \mathrm{CB}[6]+2.4 \mathrm{mM} \alpha-\mathrm{CD}$ in $\mathrm{D}_{2} \mathrm{O}$ containing $0.2 \mathrm{M} \mathrm{NaCl}$ )

The two hexyl groups of DHA are clearly discriminated from each other (shown in red and blue). 


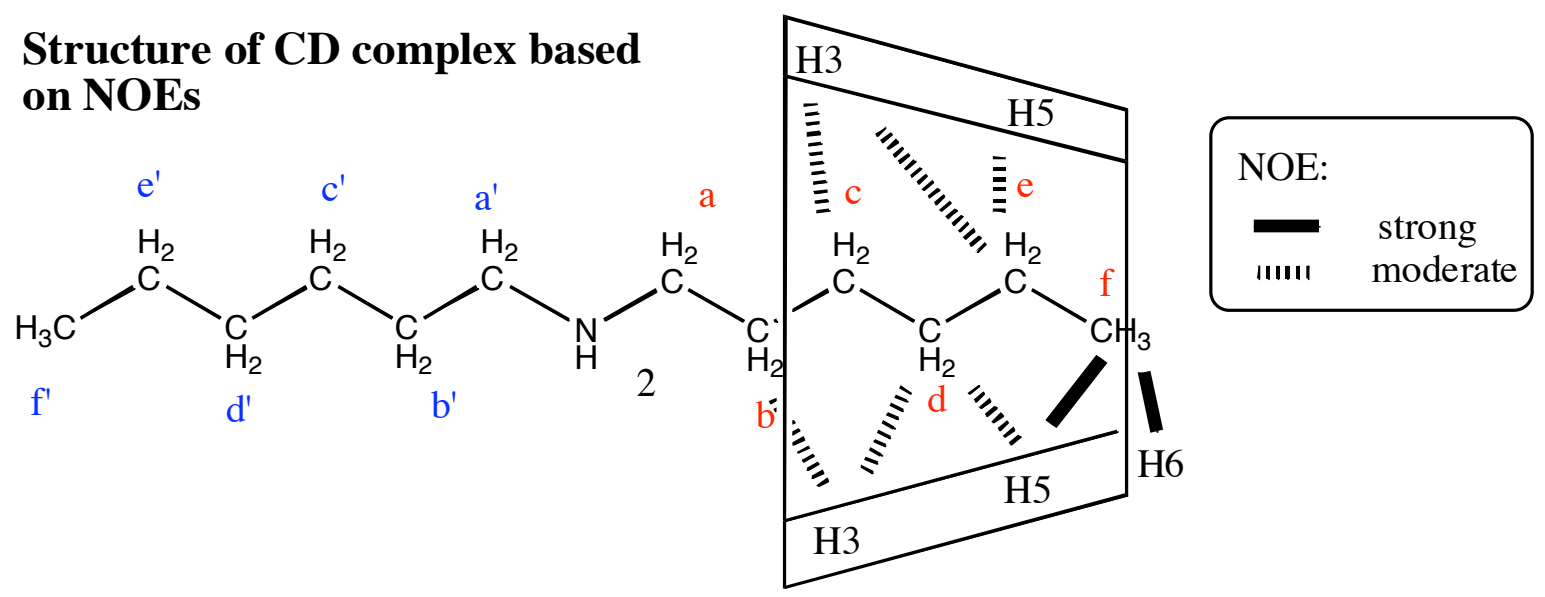

Blue: signals of CB[6]complexed hexyl group

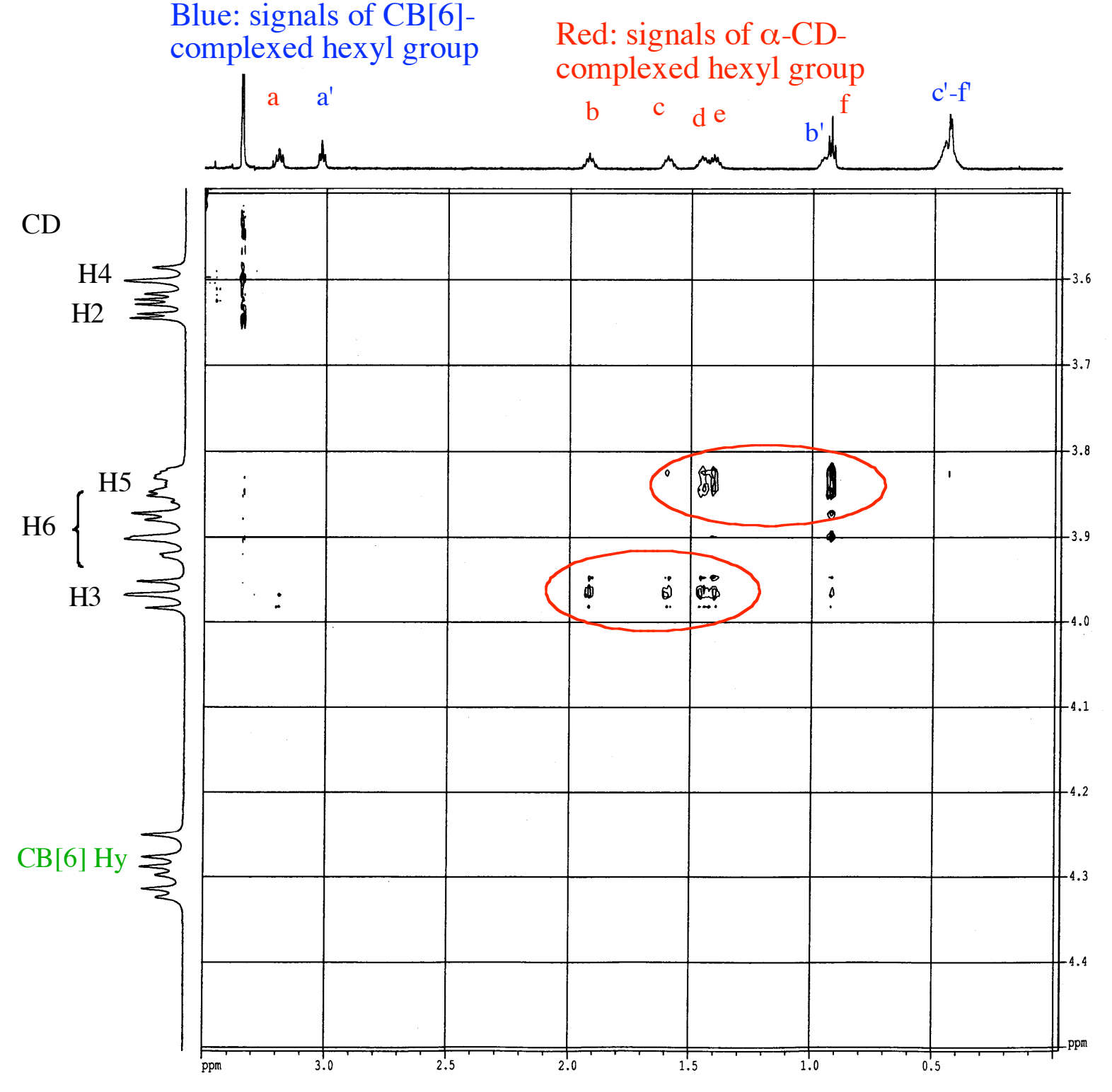

Red: signals of $\alpha-C D-$ complexed hexyl group

Figure S2-8. ROESY spectrum of a mixture of DHA, CB[6], and $\alpha-C D$ (2 mM $\mathrm{DHA} \cdot 2 \mathrm{HCl}+2.4 \mathrm{mM} \mathrm{CB}[6]+2.4 \mathrm{mM} \alpha-\mathrm{CD}$ in $\mathrm{D}_{2} \mathrm{O}$ containing $0.2 \mathrm{M} \mathrm{NaCl}$ )

One of the two hexyl groups that is included by $\mathrm{CB}[6]$ does not show any NOEs with $\alpha-C D$ 
protons, whilst the other hexyl group shows very clear crosspeaks with $\alpha$-CD protons as listed below.

\begin{tabular}{llll}
\hline DHA & \multicolumn{3}{c}{$\alpha$-CD protons } \\
\cline { 2 - 4 } protons & H3 & H5 & H6 \\
\hline $\mathrm{Ha}$ & no & no & no \\
$\mathrm{Hb}$ & medium & no & no \\
$\mathrm{Hc}$ & medium & weak & no \\
$\mathrm{Hd}$ & medium & medium & no \\
$\mathrm{He}$ & medium & medium & no \\
$\mathrm{Hf}$ & weak & strong & strong \\
\hline
\end{tabular}

These NOEs indicate that the hexyl group penetrates into the CD cavity from the secondary side. 

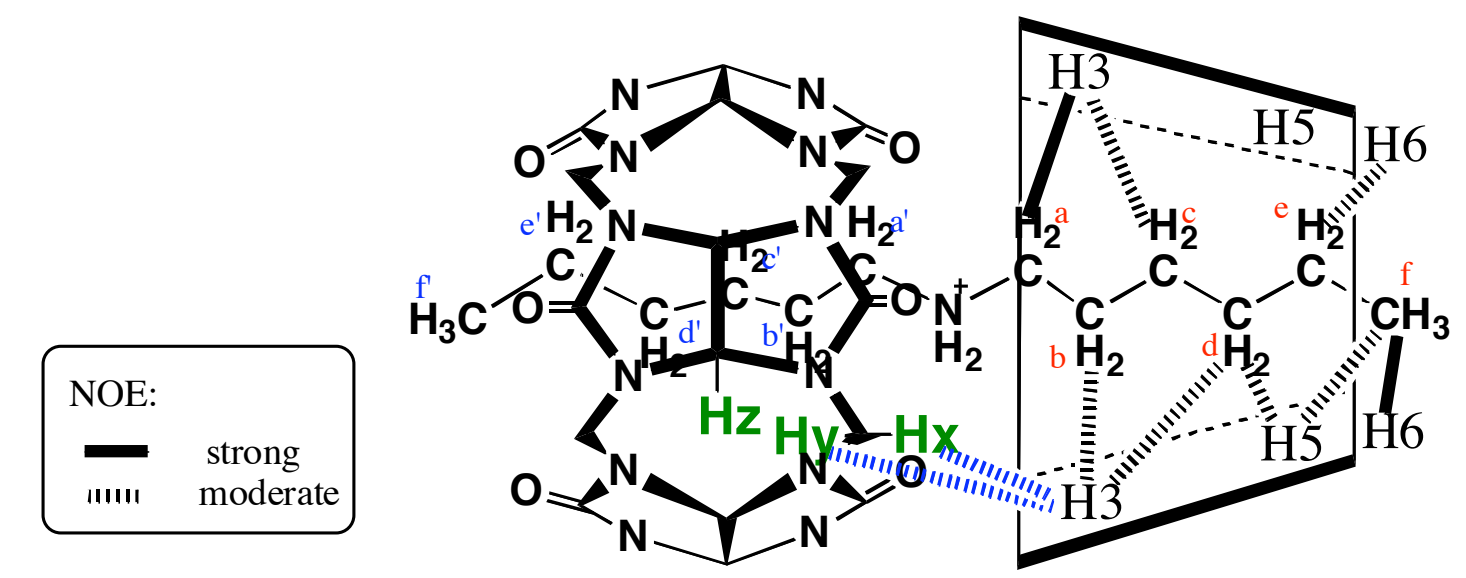

Magenta: signals of free $\mathrm{CB}[6]$

Blue: signals of complexed $\mathrm{CB}[6]$

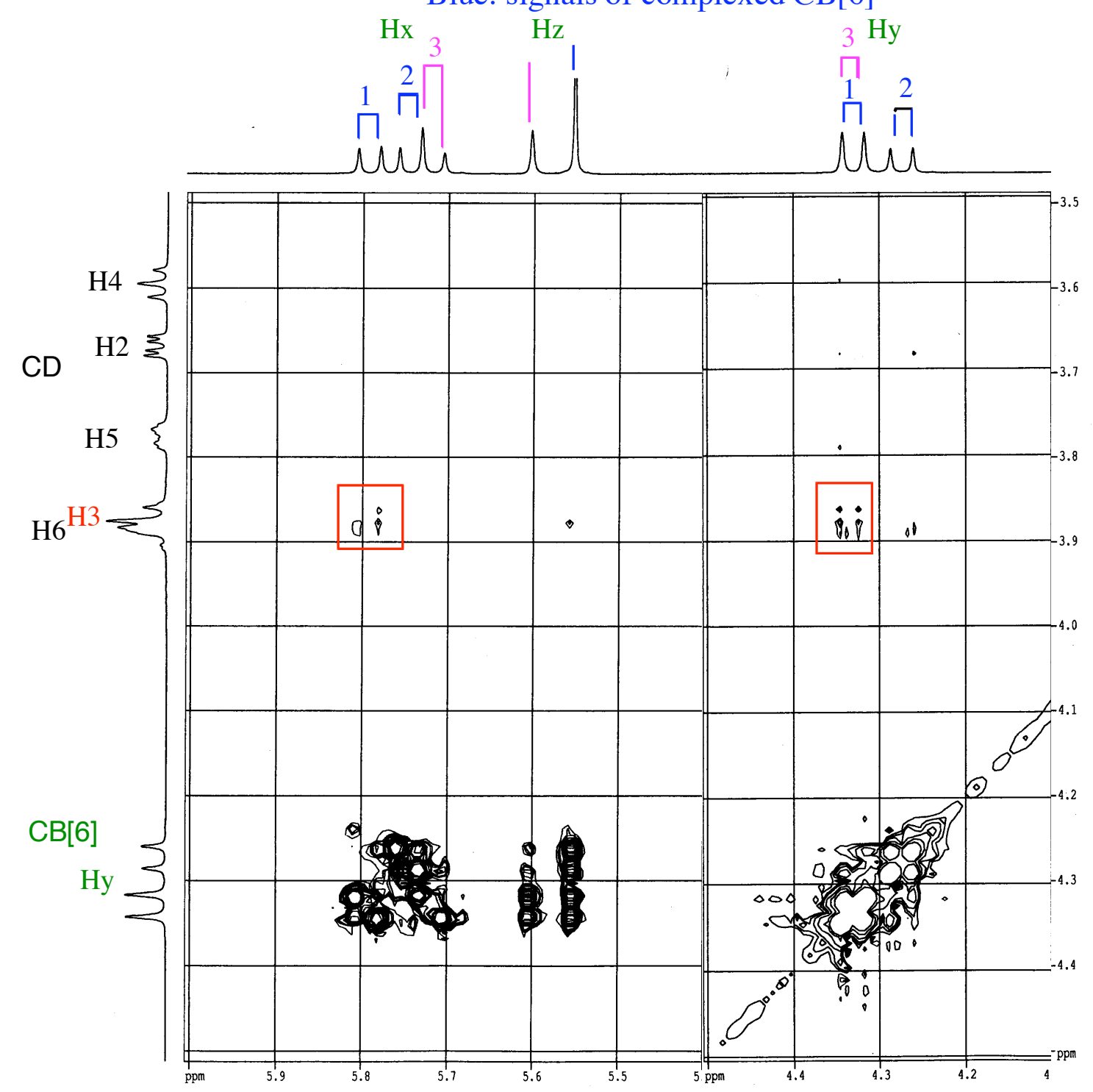

Figure S2-9. ROESY spectrum (mixing time $0.2 \mathrm{~s}$ ) of a mixture of $1 \mathrm{mM} \mathrm{DHA}+1.5$ $\mathrm{mM} \mathrm{CB}[6]+1.1 \mathrm{mM} \beta-\mathrm{CD}$ in $\mathrm{D}_{2} \mathrm{O}$ containing $4 \mathrm{mM} \mathrm{HCl}$ and $0.2 \mathrm{M} \mathrm{NaCl}(\mathrm{CB}[6]$ part)

Moderate crosspeaks between CD's H3 and CB[6]'s Hx1 and Hy1 are seen, indicating the capping complexation of $\mathrm{CD}$ to the DHA-CB[6] complex. 


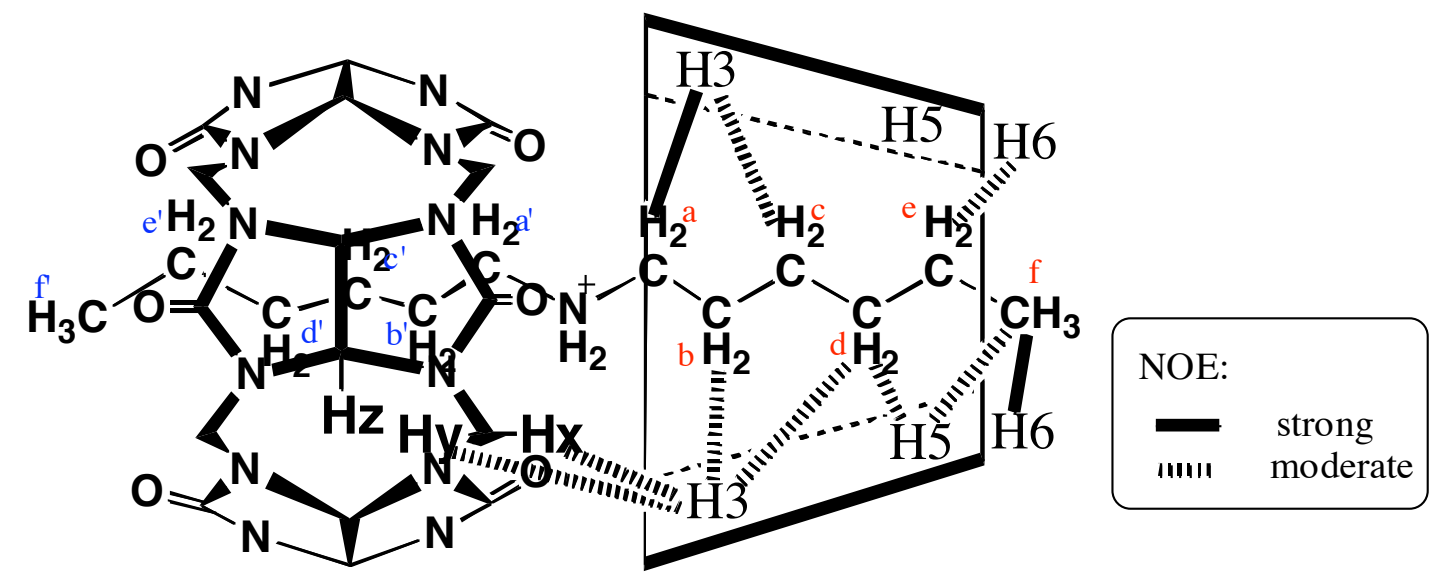

Blue: signals of $\mathrm{CB}[6]-$ complexed hexyl group

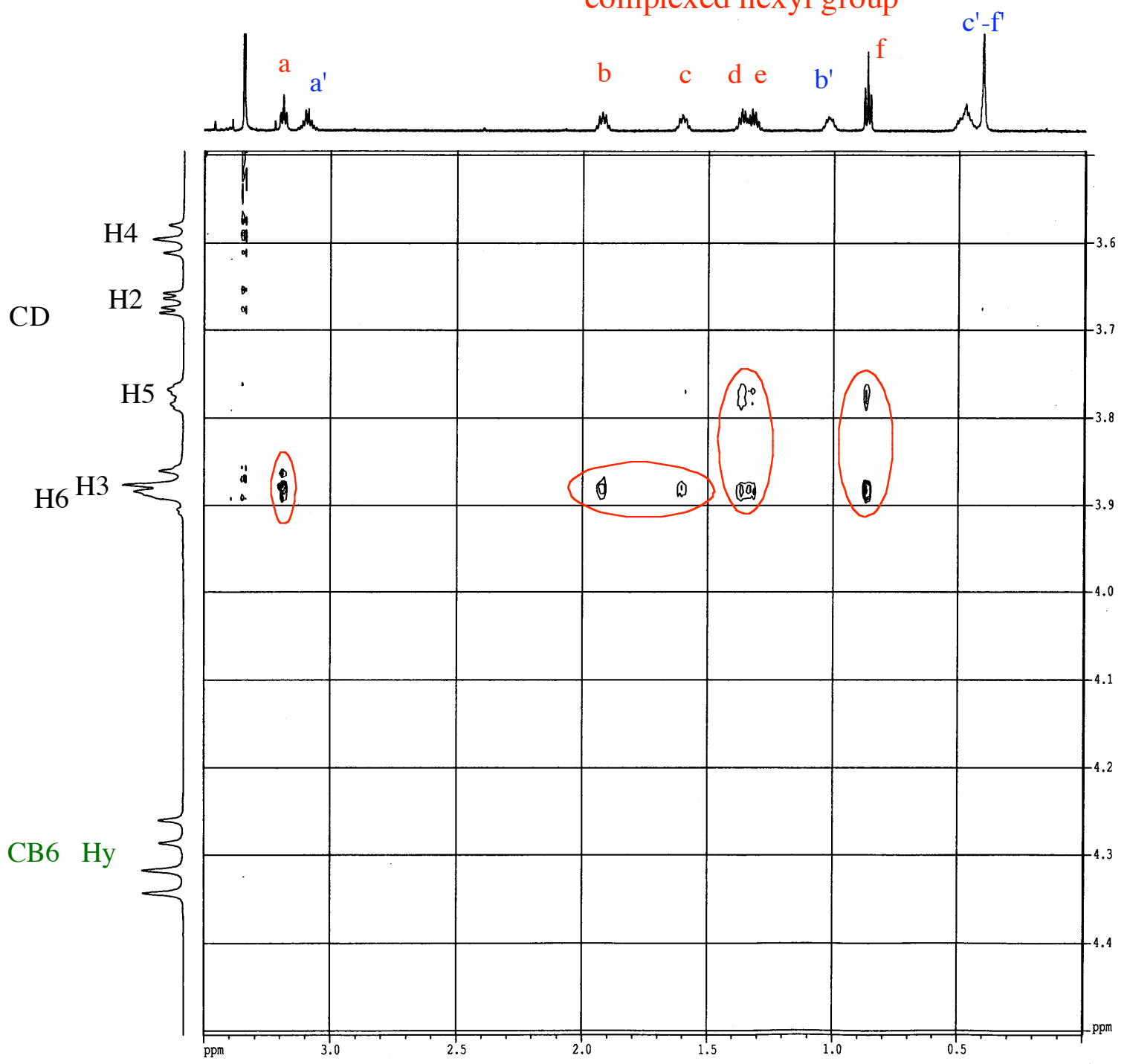

Figure S2-10. ROESY spectrum (mixing time $0.2 \mathrm{~s}$ ) of a mixture of $1 \mathrm{mM} D H A+1.5$ $\mathrm{mM} \mathrm{CB}[6]+1.1 \mathrm{mM} \beta-\mathrm{CD}$ in $\mathrm{D}_{2} \mathrm{O}$ containing $4 \mathrm{mM} \mathrm{HCl}$ and $0.2 \mathrm{M} \mathrm{NaCl}(\beta-\mathrm{CD}$ part)

One of the two hexyl groups that is included by $\mathrm{CB}[6]$ does not show any NOEs with $\beta$-CD protons, whilst the other hexyl group shows very clear crosspeaks with $\beta$-CD protons as listed 
below.

\begin{tabular}{llll}
\hline DHA & \multicolumn{3}{c}{$\beta$-CD protons } \\
\cline { 2 - 4 } protons & H3 & H5 & H6 \\
\hline $\mathrm{Ha}$ & strong & no & no \\
$\mathrm{Hb}$ & medium & no & no \\
$\mathrm{Hc}$ & medium & no & no \\
$\mathrm{Hd}$ & medium & medium & no \\
$\mathrm{He}$ & no & no & medium \\
$\mathrm{Hf}$ & no & medium & strong \\
\hline
\end{tabular}

These NOEs indicate that the hexyl group penetrates into the CD cavity from the secondary side.

\section{Summary of the NMR Studies}

One of the two hexyl groups of dihexylamine (DHA) accommodated in the CB[6] cavity showed drastic chemical shift changes, while the other hexyl group included in CD gave clear NOE crosspeaks with CD's H3 protons in the ROESY spectra. These NMR spectral examinations confirmed the formation of a ternary complex of DHA with $\mathrm{CB}[6]$ and $\mathrm{CD}$, as indicated by microcalorimetric titrations. 
3. ITC Data for the Complexation of $\alpha-, \beta-$, and $\gamma$-Cyclodextrin toward Dihexylamine (DHA) - Cucurbituril (CB[6]) 1:1 Complex.

- beddh3c6_NDH

bcddh3c6 Fit

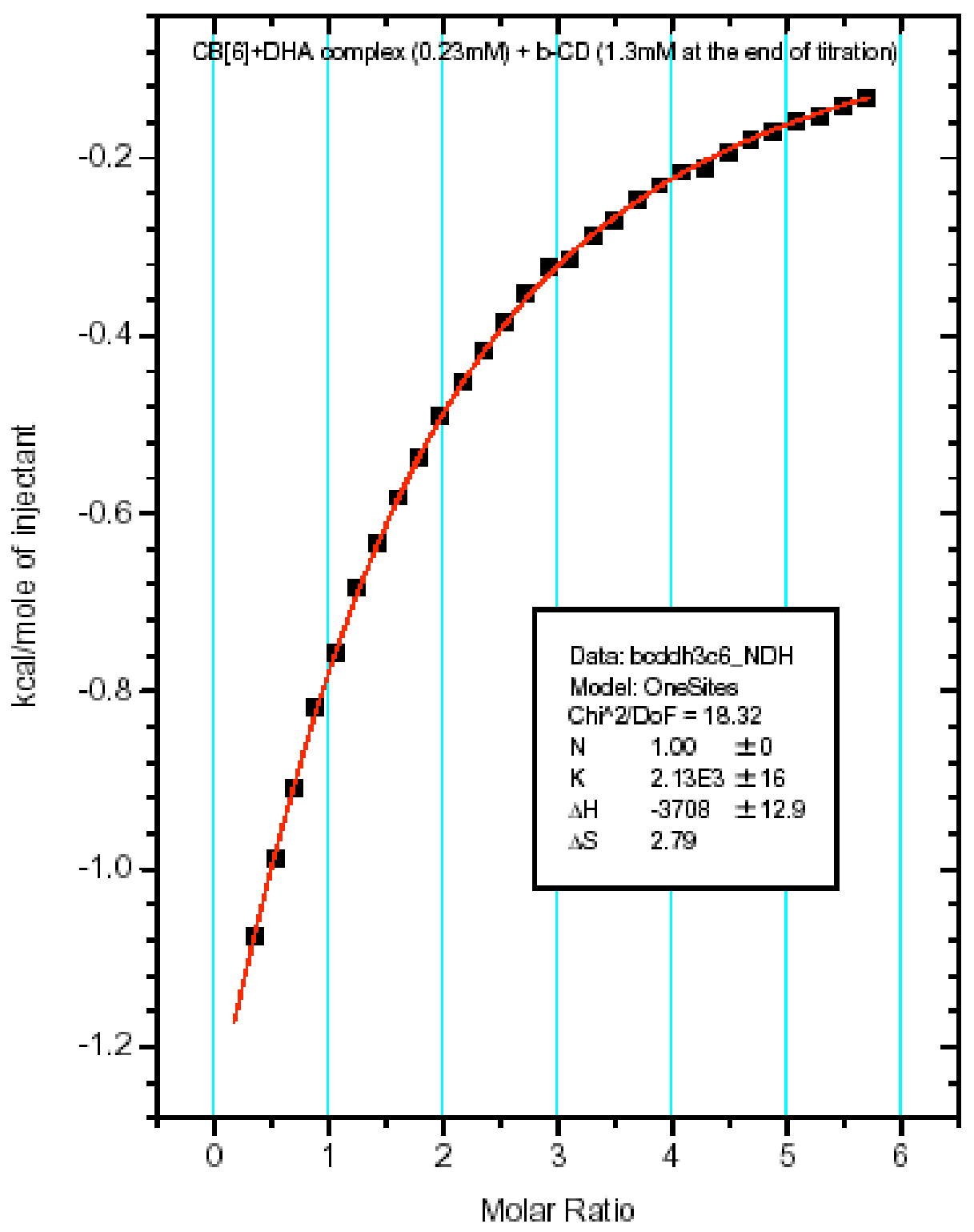

Figure S3-1. Computer simulation of ITC titration curve in the case of complexation of $\beta$-CD toward 1:1 DHA-CB[6] complex. 
- bcddh3c6 NDH

- bcddh3dl $\mathrm{NDH}$

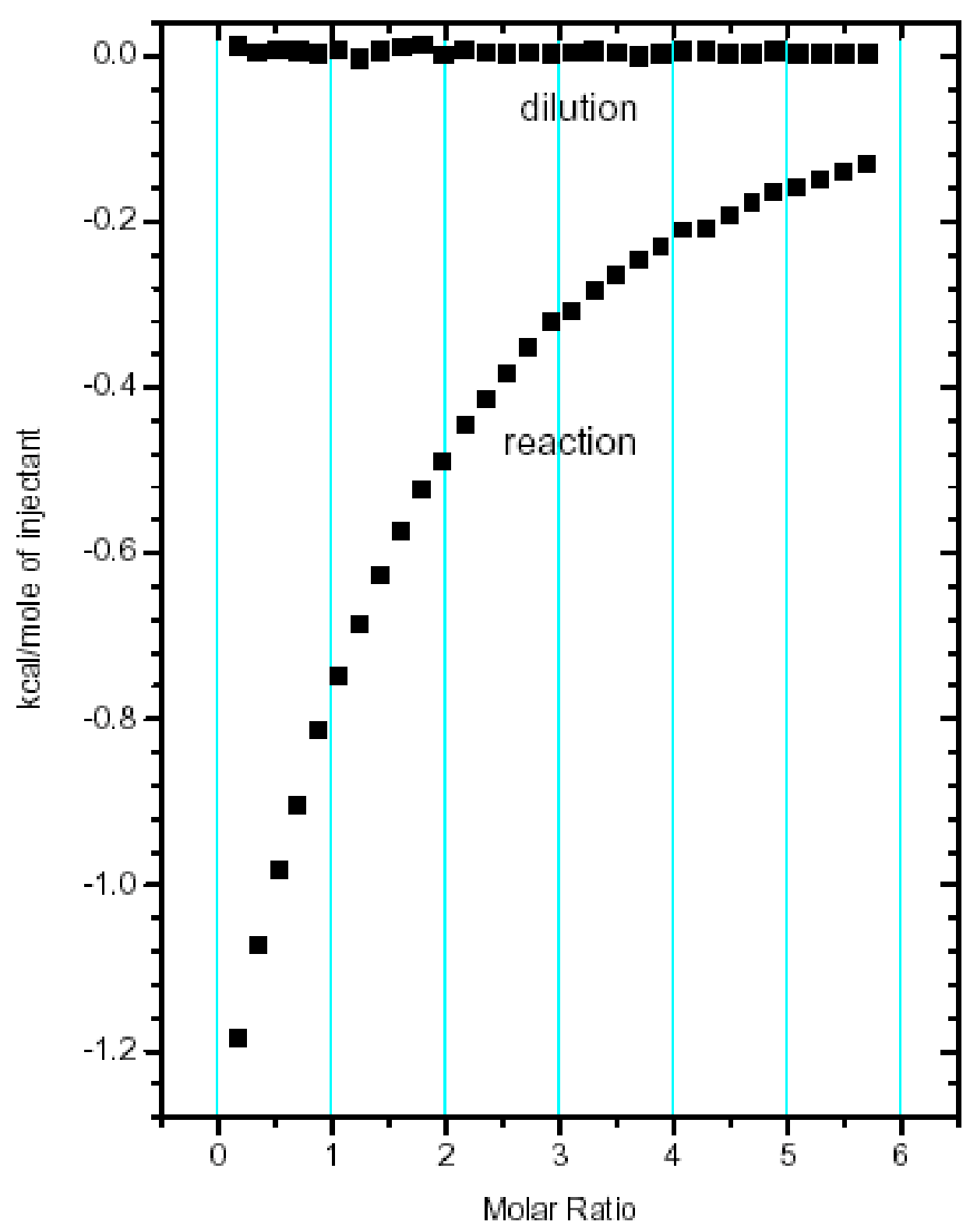

Figure S3-2. Heat effects observed upon titration of $\beta-C D$ solution into solution of DHA-CB[6] complex (reaction) and upon dilution of initial $\beta-C D$ solution (dilution); concentration of reactants shown at Figure S3-1. 


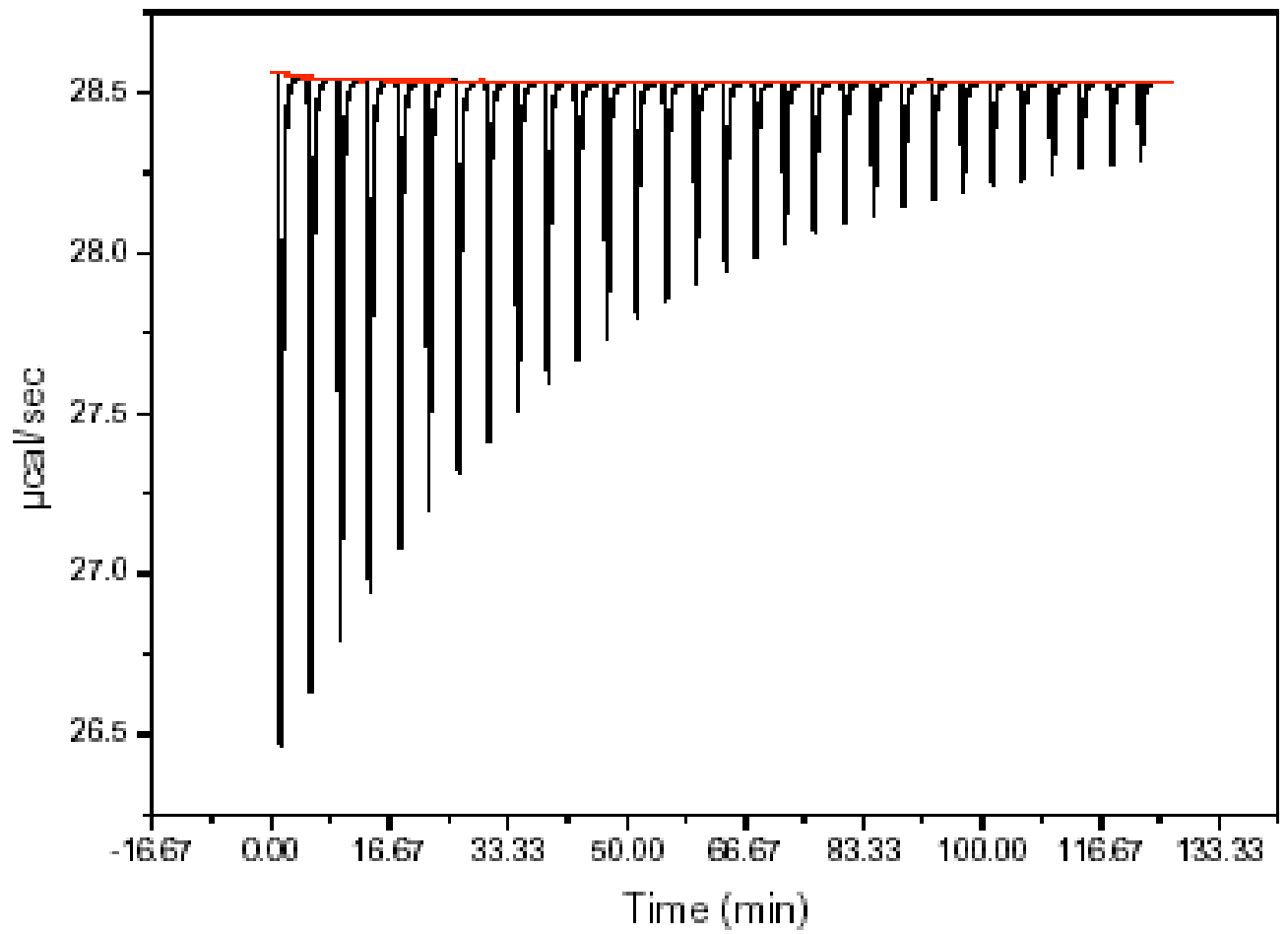

Figure S3-3. Raw ITC data for titration of $\beta-C D$ solution into solution of DHA-CB[6] complex. 
- acddh3c6_NDH acddh3c6_Fit

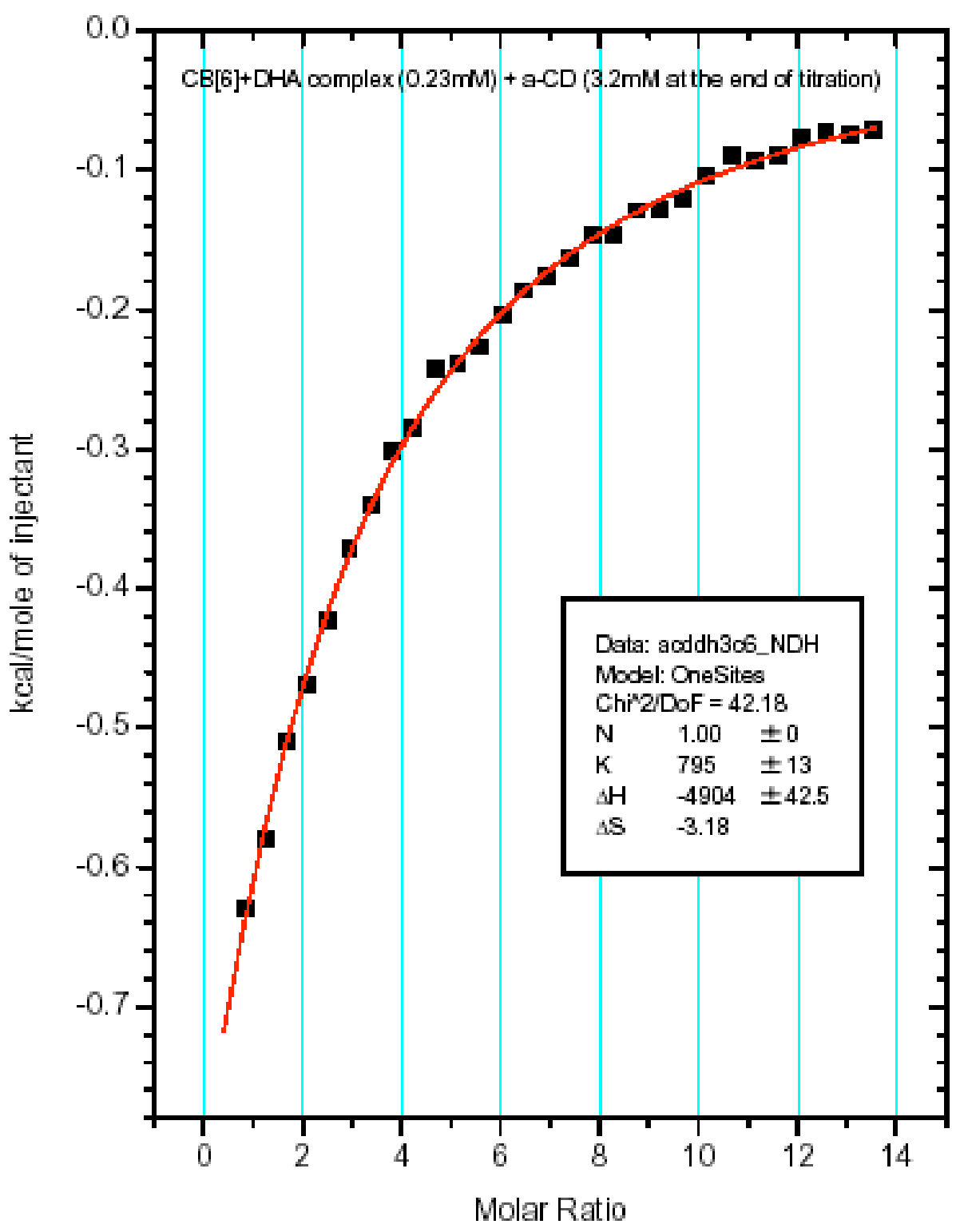

Figure S3-4. Computer simulation of ITC titration curve in the case of complexation of $\alpha-C D$ toward 1:1 DHA-CB[6] complex. 


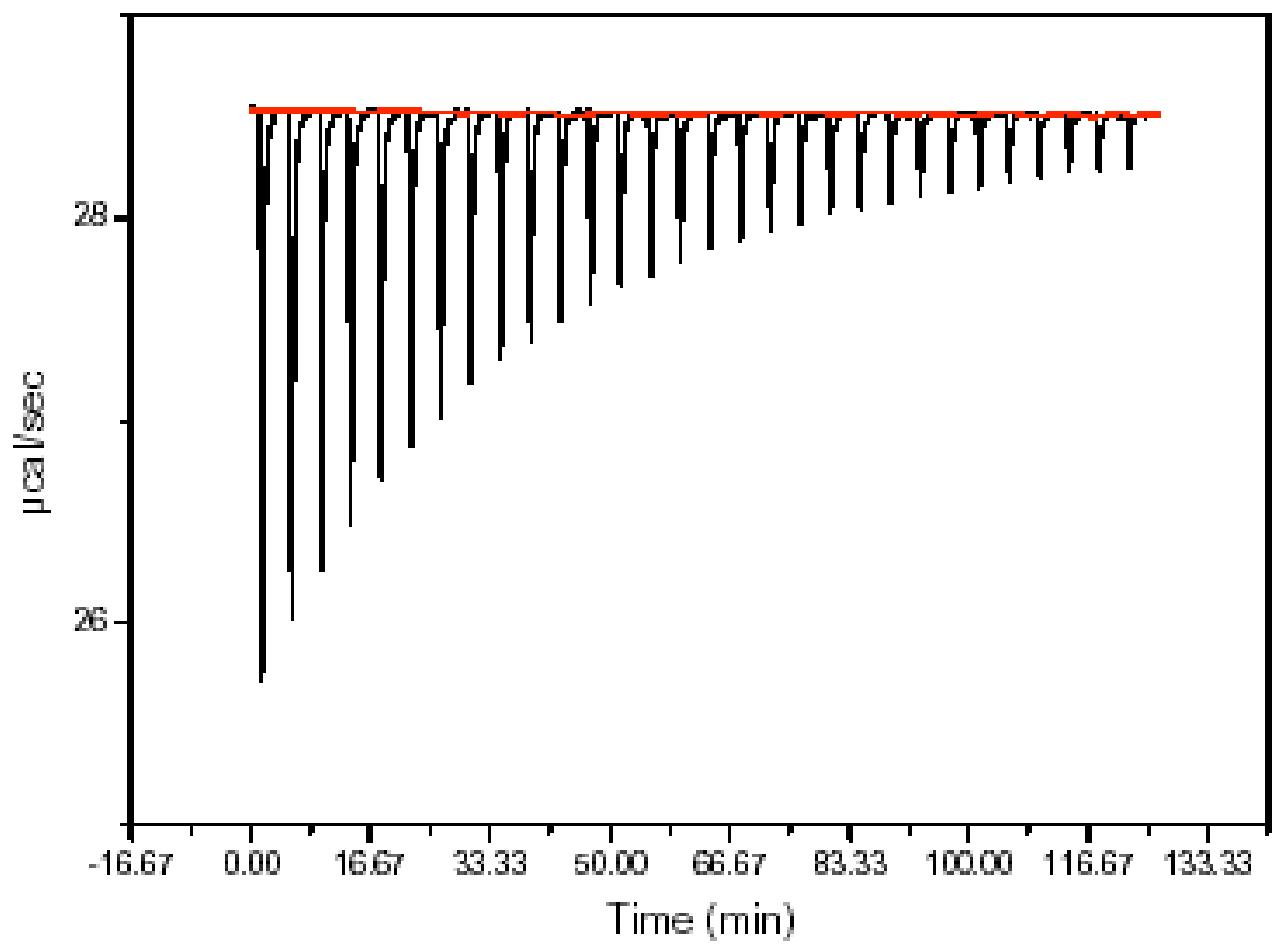

Figure S3-5. Raw ITC data for titration of $\alpha-C D$ solution into solution of DHA-CB[6] complex; concentration of reactants shown at Figure S3-4. 
- gcddh3c6_NDH gcddh3c6_Fit

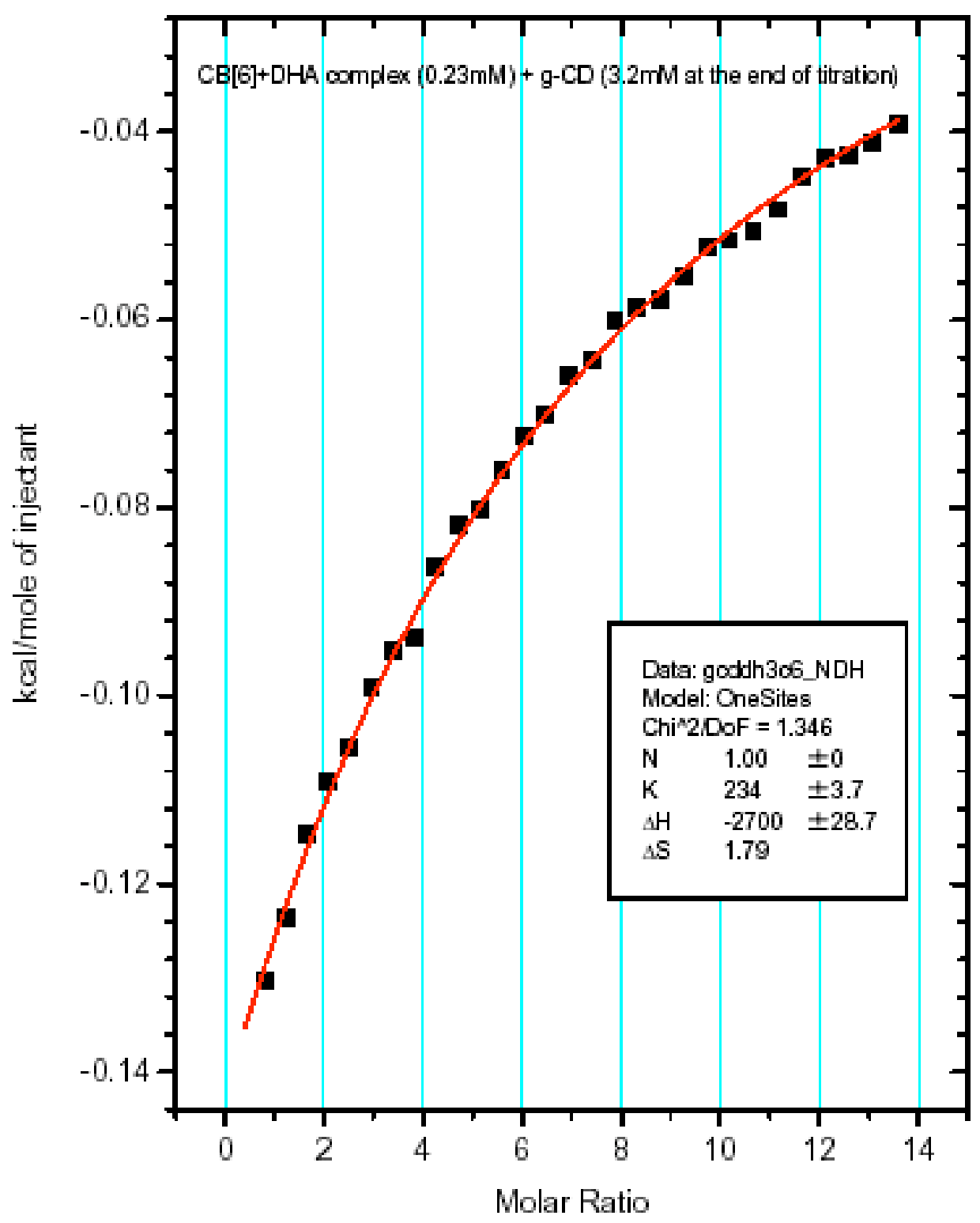

Figure S3-6. Computer simulation of ITC titration curve in the case of complexation of $\gamma$-CD toward 1:1 DHA-CB[6] complex 


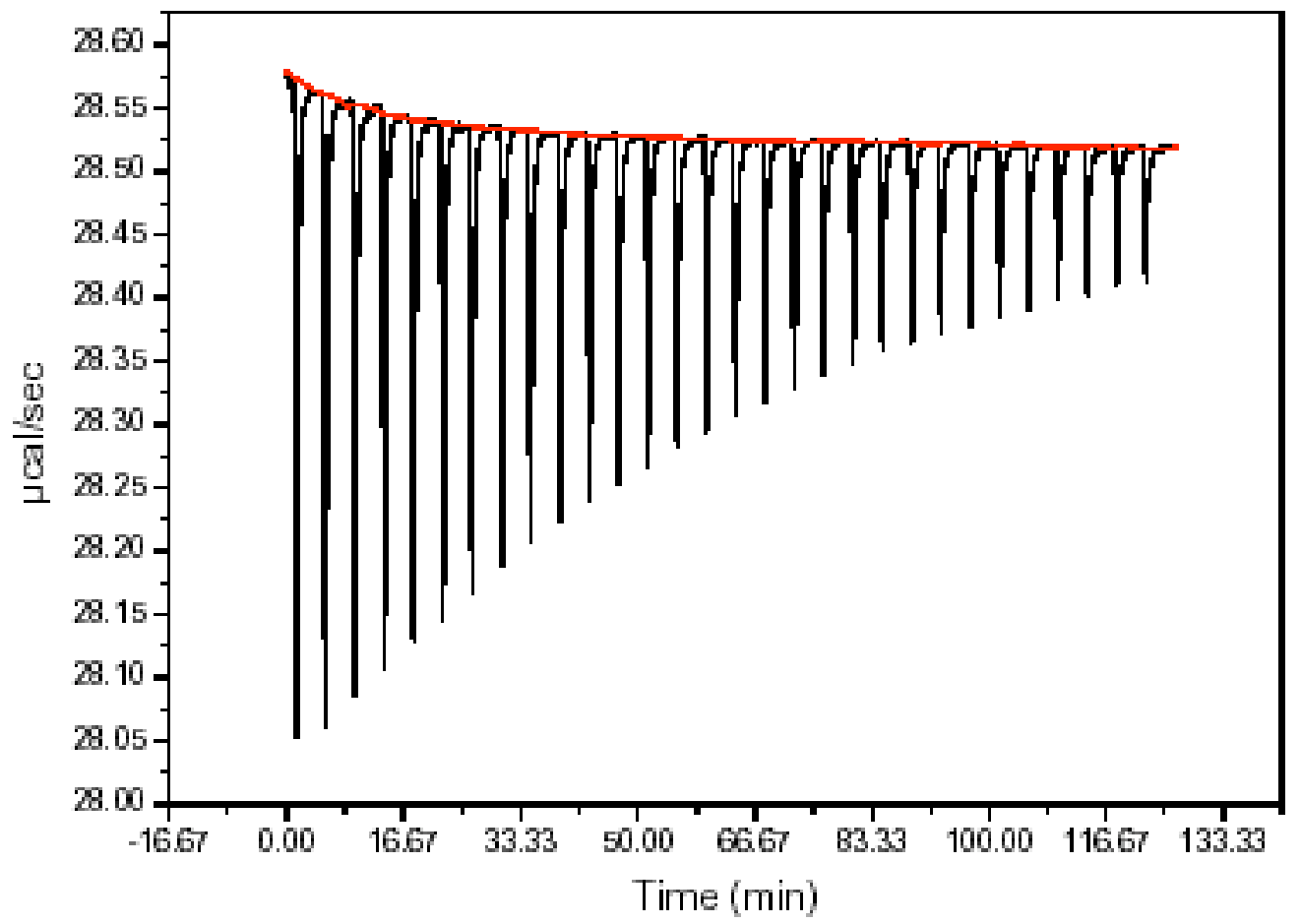

Figure S3-7. Raw ITC data for titration of $\alpha$-CD solution into solution of DHA-CB[6] complex; concentration of reactants shown at Figure S3-6. 